\title{
Optimization of Rubber Seed Oil Transesterification to Biodiesel Using Experimental Designs and Artificial Neural Networks
}

\author{
Konan Edmond Kouassi',2, Abollé Abolle²*, Kouassi Benjamin Yao1, David Boa², \\ Kopoin Adouby ${ }^{1}$, Patrick Drogui ${ }^{3}$, Rajeshwar Dayal Tyagi ${ }^{3}$
}

\footnotetext{
${ }^{1}$ Laboratoire de Procédés Industriels, de Synthèse, de l'Environnement, et des Energies Nouvelles, Groupe des Procédés et Environnement, Institut National Polytechnique Félix Houphouët-Boigny, Yamoussoukro, Côte d'Ivoire

${ }^{2}$ Laboratoire de Thermodynamique et Physico-Chimie du Milieu, UFR Sciences Fondamentales et Appliquées, Université Nangui Abrogoua, Abidjan, Côte d'Ivoire

${ }^{3}$ Institut National de la Recherche Scientifique (INRS-Centre Eau, Terre et Environnement), Université du Québec, Québec, Canada

Email: *abolle_g@hotmail.com
}

How to cite this paper: Kouassi, K.E., Abolle, A., Benjamin Yao, K., Boa, D., Adouby, K., Drogui, P. and Tyagi, R.D. (2018) Optimization of Rubber Seed Oil Transesterification to Biodiesel Using Experimental Designs and Artificial Neural Networks. Green and Sustainable Chemistry, 8, 39-61.

https://doi.org/10.4236/gsc.2018.81004

Received: December 1, 2017

Accepted: February 3, 2018

Published: February 6, 2018

Copyright (๑) 2018 by authors and Scientific Research Publishing Inc. This work is licensed under the Creative Commons Attribution International License (CC BY 4.0).

http://creativecommons.org/licenses/by/4.0/

\begin{abstract}
The development of biofuels is driven both by concern about the greenhouse effect and by interest in the opportunities for exploitation of biomass of agricultural origin. In order to improve the yield and quality of biodiesel through modeling and optimization, several studies are in progress. In this paper, biodiesel produced from rubber seed oil in the homogeneous transesterification is studied using a Plackett-Burman experimental design, a full factorial design, a central composite design and an Artificial Neural Network (ANN) coupled with a Genetic Algorithm (GA).Variables such as temperature, stirring speed, reaction time, type of alcohol, and type of catalyst are studied to obtain the best specific gravity and kinematic viscosity. Type of alcohol and type of catalyst have the greatest effect on the two responses, with ethanol (alcohol) and sulphuric acid (catalyst) producing the best results. The specific gravity and kinematic viscosity changes recorded during the transesterification process followed the first and second order polynomial models, respectively. The ANN coupled with GA was used to optimize the two responses simultaneously. Global optimal values of specific gravity $(0.883)$ and kinematic viscosity $(6.76 \mathrm{cSt})$ were recorded when a temperature of $90^{\circ} \mathrm{C}$, a stirring speed of $305 \mathrm{rpm}$, and a treatment time of 141 min were imposed.
\end{abstract}




\section{Keywords}

Rubber Seed Oil, Biodiesel, Transesterification, Specific Gravity, Kinematicviscosity

\section{Introduction}

The dramatic growth in global energy demand in recent decades can be traced mainly to the requirements of transport and industry [1] [2] [3]. Oil and hydroelectric sources are insufficient to meet this demand. Besides, the producer of oil often causes dramatic fluctuations of the price of oil, with worldwide economic consequences, especially in developing countries [4].

The use of fossil energy also has adverse effects on the environment, including global warming and climate change [1] [2] [5]. These concerns have drawn the attention of researchers to the potential of biofuels [2] [6] [7] [8]. Because they are extensively available in tropical zone and that they result from classic and simple process, vegetable oils have been targeted for exploitation as biofuel [3] [4] [9] [10] [11]. However, the viscosity and density of these oils are critical parameters determining their potential for use as fuel, affecting both the injection system (flow, maximum pressure, injection timing) and the spraying mechanism in the combustion chamber of engines [12].

The high viscosity of vegetable oils has led some users to heat them before injection, to dilute them in conventional diesel, or to modify the injectors of the engines [13] [14]. Since the direct use of crude vegetable oils is technically impracticable for traditional diesel engines, some form of processing is required to render them suitable for use as biodiesel [2] [5] [7] [14].

Five paths are available for this purpose: dilution, micro-emulsification, pyrolysis, co-feeding and co-processing with fossil feedstock material and transesterification. The last approach offers the potential for industrialization, with glycerine as a by-product [10].

The basic catalysts as the hydroxide of potassium $(\mathrm{KOH})$ and the hydroxide of sodium $(\mathrm{NaOH})$ are generally used. In the other side, sulfuric acid and chlorhydric acid were usually uses as acidic catalysts the transestérification of the vegetable oils [17].

Indeed, transesterification is a chemical reaction during which the esters are transformed into other esters by exchange of the alkyl group [15]. This reaction can be done either by an alcoholysis (reaction of an alcohol on an ester), or by an acidolysis (reaction of an acid on an ester), or by an esterolysis (reaction of an ester on another ester). These three types of transesterification can take place in the oil [15]. But in order to have alkyl esters with molecular weights similar to diesel, transesterification by alcoholysis was done as part of this work. Thus, the transesterification of vegetable oils is made by reacting a triglyceride with an alcohol in the presence of a catalyst. A mixture of glycerol and alkyl esters is ob- 
tained [16]. Three types of catalysts for transesterification reactions are basic catalysts, acid catalysts and, other catalysts as alkoxides or metal oxides and enzymatic catalysts [17]. Thus, in the context of the transesterifications can be carried out with basic catalysts such as potassium hydroxide $(\mathrm{KOH})$ and sodium hydroxide $(\mathrm{NaOH})$, and acid ones such as sulfuric acid and hydrochloric acid are used [17].

The oils that can be used as the raw material for biodiesel production can be classified into edible oils, non-edible oils and waste oils and fats. To minimize both food security concerns [18] and the costs of biodiesel production, current research focuses on the non-edible and waste oils and fats ones [11] [12] [18] [19].

A number of studies [19] [20] [21] [22] have examined the potential to use the transesterification process to enhance rubber seed oil (RSO) [23] [24] for biofuel. Rubber trees are cultivated for the production of natural rubber latex, and the wood from the trees is used for furniture or as firewood. Usually, most of seeds are unused and rot in the field. Annual rubber seed production is estimated to be 800 to $1200 \mathrm{~kg} / \mathrm{ha}$ /year. A seed contains approximately $40 \%$ to $50 \%$ oil [19], representing a yield of approximately $500 \mathrm{~L} / \mathrm{ha}$ /year [23] [24] [25]. According Zhu et al.'s study [19] of RRIM600 and GT1 clones in Southeast Asia, the age and size of trees influence seed yield. FAO statistical data show that about 10 million hectares of rubber plantations exist worldwide, representing a potential oil production of as much as 5 billion litres per year. This constitutes a significant source of raw material for the synthesis of biodiesel. In most cases, however, this oil has a high level of free fatty acids [20] [21] [22] [26], requiring a two-step process to produce biodiesel: acid esterification followed by basic transesterification or directly a transesterification in acid catalysis.

An experimental design is a statistical analysis method that determines the relationship between a dependent variable (the response $Y$ ) and explanatory variables (influencing factors $X_{i}$ ) according to Equation (1) [27]:

$$
Y=b_{0}+\sum b_{i} X_{i}+\sum b_{i j} X_{i} X_{j}+\sum b_{i j k} X_{i} X_{j} X_{k}+\sum b_{i i} X_{i}^{2}+\cdots
$$

where $b_{0}$ is the average coefficient, $b_{i}$ is the main coefficient, $b_{i j}$ is the second interaction coefficient, $b_{i j k}$ is the third interaction coefficient, $b_{i i}$ is the quadratic coefficient and $X_{p}, X_{j} X_{k}$ are the coded variables $\left(-1 \leq X_{i} \leq+1 ;-1 \leq X_{j} \leq+1\right.$; $\left.-1 \leq X_{k} \leq+1\right)$.

The coefficients were calculated using a least square method [27]. It permits to highlight the interactions between factors [27]. The mathematical model being found, optimization is defined like being the research of the values of the factors that gives according to the sought-after goal, the best value possible of the response [28]. Several works aiming to optimize the reaction of transestérification for an industrial implementation have been achieved [29] [30] [31] [32]. In most these works, the reaction yield is the main studied response. This does not only require expensive dosing methods, but also certifications of the final products. Moreover, in other works, the yield is simply expressed by the ratio of the 
mass of biodiesel to that of the oil [33] [34]. However, in homogeneous catalysis, the separation of the glycérol and the biodiesel not being always clean, a part of the biodiesel meets in the phase glycérineuse and vice versa, blemishing mistake the evaluation of the yield. It is why, we consider in this work a new approach of optimization while studying as responses the parameters of quality of the biodiesel (the specific gravity and the kinematic viscosity) closely bound to the yield of the reaction [35].

A number of approaches have been considered for modeling and optimizing biodiesel production from rubber seed oil, but knowledge of the actual weight of the different factors affecting the quality of the final product remains incomplete. The goal of this study was to elucidate the effect of each of these factors, individually and in combination, on the quality of the product. The factors involved in the synthesis of biodiesel [27] [28] were first screened using a Hadamard matrix. A full factorial matrix and central composite design response surface methodology were then used to model and optimize the synthesis, focusing on specific gravity and viscosity. Finally, an Artificial Neural Network (ANN) coupled with a Genetic Algorithm (GA) was used to produce a global optimization of the process.

\section{Materials and Methods}

\subsection{Raw Material and Chemicals}

The crude oil was extracted from rubber seeds collected from private and industrial plantations in Côte d'Ivoire. The seeds were dried, crushed, and pressed with a mechanical press. The composition of the brown oil obtained is shown in SM 1. The main chemicals used in the study (potassium hydroxide $(\mathrm{KOH})$ pellets of 85 wt.\% purity, sulphuric acid $\left(\mathrm{H}_{2} \mathrm{SO}_{4}\right)$ of 96 wt.\% purity, methanol $(\mathrm{MeOH})$ of $99.7 \mathrm{wt} . \%$ purity, ethanol (EtOH) of $99 \mathrm{wt} . \%$ purity, and magnesium sulphate $\left(\mathrm{MgSO}_{4}\right)$ of 99 wt.\% purity) were provided by Merck Ltd (Germany).

\subsection{Transesterification Procedure}

The transesterification was carried out in liquid phase under various conditions according to the experimental design. In alkaline conditions, the synthesis of biodiesel was carried out with a molar ratio $\mathrm{MeOH} /$ oil (or EtOH/oil) of 6:1 and $1 \%(\mathrm{w} / \mathrm{w})$ of $\mathrm{KOH}$ relative to the oil, while in acidic conditions, a molar ratio $\mathrm{MeOH} / \mathrm{oil}$ (or EtOH/oil) of $6: 1$ and $2.25 \%(\mathrm{~mol} / \mathrm{mol}$ ) of the mixture were used according to Mohamad et al. (2002) [36]. Two alcohols were used, $\mathrm{MeOH}$ and EtOH. The experimental set-up used was a $500 \mathrm{~mL}$ batch reactor magnetically stirred and equipped with a heater This reactor is surmounted by a coolant to prevent the alcohol from evaporating, especially when the reaction reaction takes place beyond the boiling temperature of the alcohol. At the end of the reaction, the mixture was collected and subjected to settling. The upper layer was then collected and washed with hot distilled water. The moisture in the washed biodiesel was subsequently removed using anhydrous $\mathrm{MgSO}_{4}$. 
SM 1. Fatty acid profile of crude rubber seed oil (RSO) (analysis by gaz chromatogrphy coupled with a Detector of Flame ionization (GC/DFI) Hewlett-Packard ${ }^{\circledR} 5890$ II set provided with an automatic sample ferryman of Agilent 6890).

\begin{tabular}{ccc}
\hline Fatty acids & Number of carbon & Composition w/w (\%) \\
\hline lauric & $\mathrm{C} 12$ & 0 \\
myristic & $\mathrm{C} 14$ & 0.09 \\
palmitic & $\mathrm{C} 16: 0$ & 8.74 \\
palmitoleic & $\mathrm{C} 16: 1$ & 0.09 \\
stearic & $\mathrm{C} 18: 0$ & 7.80 \\
oleic & $\mathrm{C} 18: 1$ & 23.84 \\
linoleic & $\mathrm{C} 18: 2$ & 38.93 \\
linolenic & $\mathrm{C} 18: 3$ & 20.28 \\
arachidic & $\mathrm{C} 20: 0$ & 0.23 \\
gadoleic & $\mathrm{C20:1}$ & 0 \\
behenic & $\mathrm{C} 22: 0$ & 0 \\
erucic & $\mathrm{C22:1}$ & 0 \\
saturated fatty acids & & 16.86 \\
unsaturated fatty acids & & 83.14 \\
\hline & & \\
\hline & & \\
\hline
\end{tabular}

\subsection{Experimental Design}

Among existing experimental designs [26], the Plackett and Burman model [37] is the most suitable for screening. In this study, the transesterification was examined using a Hadamard matrix with five factors: temperature $\left(U_{1}\right)$, stirring speed $\left(U_{2}\right)$, reaction time $\left(U_{3}\right)$, type of solvent $\left(U_{4}\right)$, and type of catalyst $\left(U_{5}\right)$. Specific gravity and kinematic viscosity were considered as the responses.

Analysis of the effects of the factors on the two responses was performed using Equation (2). In this equation $P_{i}$ is the contribution of each factor on the response.

$$
P_{i}=100 \times\left(\frac{b_{i}^{2}}{\sum b_{i}^{2}}\right) ; \quad i \neq 0
$$

where $b_{i}$ is the estimate of the main effect of factor $i$.

A full factorial matrix $\left(2^{k}, k\right.$ being the number of factors) was used for quantitative optimization of the factors. Full factorial matrices examine two or more factors, each with discrete possible values or levels, across all possible combinations of levels and factors. A full factorial design (FFD) may also be called a fully crossed design. The effect of each individual factor, and the effects of interactions between factors, can be examined using this approach. In this study, the effects of temperature $\left(U_{1}\right)$, stirring speed $\left(U_{2}\right)$, and reaction time $\left(U_{3}\right)$ were evaluated.

Response surface methodology (RSM) using a central composite design (CCD) with five levels and two factors (stirring speed and reaction time) was used for to 
model and optimize the relation between these factors and specific gravity and viscosity. The experimental runs were randomized to minimize the effects of unexpected variability in the observed responses. The methodology employed enables the formulation of a second-order polynomial that describes the process. To correlate the response variable to the independent variables, multiple regressions were used to fit the coefficient of the second-order polynomial model of the response [34].

Table 1 summarizes the experimental range and levels of the independent process variables studied for each part of this work. For screening, the main factors involved in biodiesel synthesis and their limits were chosen according to the literature [38]. The experimental domain of the full factorial design is defined from the results of the screening. Similarly, the experimental domain of central composite design is defined from the results of the full factorial design. The experimental design and responses observed during the screening are shown in Table 2.

The main interactions, correlation coefficients, variance analysis, residuals, and standard deviations were calculated using the NEMROD-W program (design NEMROD-W, version 9901 Française, LPRAI-Marseille Inc., France).

Table 1. Experimental range and levels of independent process variables.

\begin{tabular}{|c|c|c|c|}
\hline \multirow{2}{*}{ Coded variables $\left(X_{\mathrm{i}}\right)$} & \multirow{2}{*}{ Factors $\left(U_{\mathrm{i}}\right)$} & \multicolumn{2}{|c|}{ Experimental field } \\
\hline & & Min value & Max value \\
\hline \multicolumn{4}{|c|}{ Screening } \\
\hline$X_{1}$ & Temperature $\left(U_{1}\right)$ & $30^{\circ} \mathrm{C}$ & $80^{\circ} \mathrm{C}$ \\
\hline$X_{2}$ & Stirring speed $\left(\mathrm{U}_{2}\right)$ & $300 \mathrm{rpm}$ & $1100 \mathrm{rpm}$ \\
\hline$X_{3}$ & Reaction time $\left(U_{3}\right)$ & $45 \mathrm{~min}$ & $145 \mathrm{~min}$ \\
\hline$X_{4}$ & type of alcohol $\left(U_{4}\right)$ & $\mathrm{EtOH}$ & $\mathrm{MeOH}$ \\
\hline$X_{5}$ & Type of catalyst $\left(U_{5}\right)$ & $\mathrm{H}_{2} \mathrm{SO}_{4}$ & $\mathrm{KOH}$ \\
\hline \multicolumn{4}{|c|}{ Full factorial design } \\
\hline$X_{1}$ & Temperature $\left(U_{1}\right)$ & $70^{\circ} \mathrm{C}$ & $90^{\circ} \mathrm{C}$ \\
\hline$X_{2}$ & Stirring speed $\left(U_{2}\right)$ & $100 \mathrm{rpm}$ & $300 \mathrm{rpm}$ \\
\hline$X_{3}$ & Reaction time $\left(U_{3}\right)$ & $125 \mathrm{~min}$ & $165 \mathrm{~min}$ \\
\hline$X_{4}$ & type of alcohol $\left(U_{4}\right)$ & \multicolumn{2}{|c|}{$\mathrm{EtOH}$} \\
\hline$X_{5}$ & Type of catalyst $\left(U_{5}\right)$ & \multicolumn{2}{|c|}{$\mathrm{H}_{2} \mathrm{SO}_{4}$} \\
\hline \multicolumn{4}{|c|}{ Central composite design } \\
\hline$X_{1}$ & Temperature $\left(U_{1}\right)$ & \multicolumn{2}{|c|}{$90^{\circ} \mathrm{C}$} \\
\hline$X_{2}$ & Stirring speed $\left(U_{2}\right)$ & $200 \mathrm{rpm}$ & $400 \mathrm{rpm}$ \\
\hline$X_{3}$ & Reaction time $\left(U_{3}\right)$ & $105 \mathrm{~min}$ & $145 \mathrm{~min}$ \\
\hline$X_{4}$ & type of alcohol $\left(U_{4}\right)$ & \multicolumn{2}{|c|}{$\mathrm{EtOH}$} \\
\hline$X_{5}$ & Type of catalyst $\left(U_{5}\right)$ & \multicolumn{2}{|c|}{$\mathrm{H}_{2} \mathrm{SO}_{4}$} \\
\hline
\end{tabular}


In order to find a global optimum, a single database was established bymerging the observed responses of the full factorial and central composite design analyses. This database, described in Table 3, was used to model the process with an artificial neural network. The resulting models were then used to search for a global optimum with a genetic algorithm.

The genetic algorithm (GA) was used to determine a global optimum minimizing equations $(\mathrm{x})$ and $(\mathrm{y})$ under constraint. GAs are stochastic search techniques whose theoretical bases were defined by J. H. Holland [39]. They are based on a natural biological process: the evolution of living species. They evolve through two mechanisms: natural selection and reproduction. Selection ensures that only the fittest individuals survive, while reproduction recombines parental characteristics to create descendants with new possibilities. The combination of these two phenomena (selection and reproduction) leads, generation after generation, to populations that are better and better adapted to the environment in which they live.

Artificial neural network (ANN) is a powerful modeling tool, used in various fields. In this study, specific gravity and kinematic viscosity variation were predicted using the Multilayer Perceptron (MP) [40] [41]. The ANN architecture included an input layer with three neurons (representing temperature, stirring speed and reaction time) and an output layer with two neurons (representing specific gravity and kinematic viscosity). The optimal network topology was determined using MATLAB programm (Matlab R2015a).

The main objective was to simultaneously minimize the specific gravity and kinematic viscosity. Such an optimization was performed via aggregation of the multiple objectives into a single objective function [40] [41], as expressed by Equation (3).

Table 2. Experimental design and responses of the preliminary screening study.

\begin{tabular}{|c|c|c|c|c|c|c|c|}
\hline \multirow{3}{*}{$\begin{array}{l}\mathrm{N}^{\bullet} \\
\text { Exp. }\end{array}$} & \multicolumn{5}{|c|}{ Factors } & \multicolumn{2}{|c|}{ Responses } \\
\hline & $\begin{array}{c}\text { Temperature: } \\
U_{1}\end{array}$ & $\begin{array}{l}\text { Stirring } \\
\text { speed: } U_{2}\end{array}$ & $\begin{array}{l}\text { Reaction } \\
\text { time: } U_{3}\end{array}$ & $\begin{array}{c}\text { Type of } \\
\text { alcohol. } U_{4}\end{array}$ & $\begin{array}{l}\text { Type of } \\
\text { catalyst: } U_{5}\end{array}$ & $\begin{array}{c}\text { Specific } \\
\text { gravity } \\
\left(15^{\circ} \mathrm{C}\right): Y_{1}\end{array}$ & $\begin{array}{l}\text { Kinematic } \\
\text { viscosity } \\
\left(37.8^{\circ} \mathrm{C}\right): Y_{2}\end{array}$ \\
\hline & $\left({ }^{\circ} \mathrm{C}\right)$ & (rpm) & $(\min )$ & & & & $(\mathrm{cSt})$ \\
\hline 1 & 80 & 1100 & 145 & $\mathrm{EtOH}$ & $\mathrm{KOH}$ & 0.885 & 7.08 \\
\hline 2 & 30 & 1100 & 145 & $\mathrm{MeOH}$ & $\mathrm{H}_{2} \mathrm{SO}_{4}$ & 0.898 & 10.18 \\
\hline 3 & 30 & 300 & 145 & $\mathrm{MeOH}$ & $\mathrm{KOH}$ & 0.891 & 8.25 \\
\hline 4 & 80 & 300 & 45 & $\mathrm{MeOH}$ & $\mathrm{KOH}$ & 0.894 & 10.35 \\
\hline 5 & 30 & 1100 & 45 & $\mathrm{EtOH}$ & $\mathrm{KOH}$ & 0.885 & 7.70 \\
\hline 6 & 80 & 300 & 145 & EtOH & $\mathrm{H}_{2} \mathrm{SO}_{4}$ & 0.901 & 9.72 \\
\hline 7 & 80 & 1100 & 45 & $\mathrm{MeOH}$ & $\mathrm{H}_{2} \mathrm{SO}_{4}$ & 0.894 & 8.06 \\
\hline 8 & 30 & 300 & 45 & $\mathrm{EtOH}$ & $\mathrm{H}_{2} \mathrm{SO}_{4}$ & 0.901 & 10.44 \\
\hline
\end{tabular}


Table 3. ANN data base.

\begin{tabular}{|c|c|c|c|c|c|}
\hline \multirow[b]{2}{*}{ Run } & \multicolumn{3}{|c|}{ Factors } & \multicolumn{2}{|c|}{ Responses } \\
\hline & $\begin{array}{l}\text { Temperature } \\
\left({ }^{\circ} \text { C) } X_{1}\right.\end{array}$ & $\begin{array}{l}\text { Stirring Speed } \\
\quad(\mathrm{rpm}) X_{2}\end{array}$ & $\begin{array}{l}\text { Reaction time } \\
\text { (min) } X_{3}\end{array}$ & $\begin{array}{l}\text { specific gravity } \\
\text { at } 29^{\circ} \mathrm{C}\end{array}$ & $\begin{array}{c}\text { Kinematic } \\
\text { Viscosity } \\
\text { (cSt) at } 37.8^{\circ} \mathrm{C}\end{array}$ \\
\hline 1 & 90 & 300 & 125 & 0.885 & 7.08 \\
\hline 2 & 70 & 300 & 125 & 0.898 & 10.18 \\
\hline 3 & 90 & 100 & 125 & 0.891 & 8.25 \\
\hline 4 & 70 & 100 & 125 & 0.894 & 10.35 \\
\hline 5 & 90 & 300 & 165 & 0.885 & 7.70 \\
\hline 6 & 70 & 300 & 165 & 0.901 & 9.72 \\
\hline 7 & 90 & 100 & 165 & 0.894 & 8.06 \\
\hline 8 & 70 & 100 & 165 & 0.901 & 10.44 \\
\hline 9 & 80 & 200 & 145 & 0.894 & 7.71 \\
\hline 10 & 80 & 200 & 145 & 0.893 & 7.66 \\
\hline 11 & 80 & 200 & 145 & 0.895 & 8.62 \\
\hline 12 & 90 & 230 & 110 & 0.887 & 7.37 \\
\hline 13 & 90 & 370 & 110 & 0.886 & 7.26 \\
\hline 14 & 90 & 230 & 140 & 0.885 & 7.17 \\
\hline 15 & 90 & 370 & 140 & 0.885 & 7.01 \\
\hline 16 & 90 & 200 & 125 & 0.886 & 7.34 \\
\hline 17 & 90 & 400 & 125 & 0.885 & 7.14 \\
\hline 18 & 90 & 300 & 105 & 0.888 & 7.44 \\
\hline 19 & 90 & 300 & 145 & 0.885 & 7.02 \\
\hline 20 & 90 & 300 & 125 & 0.886 & 7.08 \\
\hline 21 & 90 & 300 & 125 & 0.885 & 7.07 \\
\hline 22 & 90 & 300 & 125 & 0.886 & 7.07 \\
\hline 23 & 90 & 300 & 125 & 0.885 & 7.10 \\
\hline 24 & 90 & 300 & 125 & 0.885 & 7.09 \\
\hline
\end{tabular}

$\operatorname{Min} Y$;

with $Y=Y_{1}+Y_{2}$

$70 \leq X_{1} \leq 90^{\circ} \mathrm{C}$,

$100 \leq X_{2} \leq 400 \mathrm{rpm}$,

$105 \leq X_{3} \leq 165 \mathrm{~min}$.

The computational parameters of the GA were the following: 1) population size $=200 ; 2)$ Elite count $=2 ; 3)$ Number of Generation $=1500 ; 4)$ Fitness scaling function = @fitscalingrank; 5) Selection function = Selection function; 6) Crossover function= @crossoverscattered; 7) Mutation function = @mutationuniform; 8) Mutation probability $=0.05$. 


\subsection{Analytical Techniques}

An ABBE WYA-IS refractometer was used to determine the refraction index. Kinematic viscosity was measured using a capillary tube viscometer (HVU 482). Specific gravity was determined with a DMA $4500 \mathrm{M}$ densimeter. A digital scale (OHAUS) with a precision of $0.001 \mathrm{~g}$ was used to measure weight. Physicochemical characteristics such as acid, ester, peroxide, iodine, and saponification index, water and volatile matter content, specific gravity, viscosity, cetane index, refractive index, and heating value were determined according to the AFNOR [42] [43] and ASTM norms or by calculation [33] [44] [45]. The fatty acid profile of crude rubber seed oil is determined by gaz chromatogrphy coupled with a Detector of Flame ionization (GC/DFI) Hewlett-Packard ${ }^{\circledR} 5890$ II set provided with an automatic sample ferryman of Agilent 6890.

\section{Results and Discussion}

\subsection{Physicochemical Characteristics of the Studied Products}

The physicochemical properties determined and compared to those of the gasoil are presented in SM 2.

SM 2. Some physicochemical characteristics of rubber seed oil compared to diesel.

\begin{tabular}{|c|c|c|c|c|c|}
\hline & Unit & RSO & Diesel & $\begin{array}{l}\text { standards } \\
\text { or methods }\end{array}$ & Specifications \\
\hline Density $\left(15^{\circ} \mathrm{C}\right)$ & - & 0.929 & 0.875 & ASTM D4052 & Min 0.820 Max 0.880 \\
\hline $\begin{array}{c}\text { Kinematic } \\
\text { viscosity } 37.8^{\circ} \mathrm{C}\end{array}$ & $\mathrm{cSt}$ & 37.316 & 4.28 & ASTM D 445 & Min 1.6 Max 5.9 \\
\hline Acid value & $\mathrm{mg}$ of $\mathrm{KOH} / \mathrm{g}$ & 23.025 & 0.37 & NFT60-204 & Max 0.50 \\
\hline Acidity or FFA & $\%$ & 11.57 & - & NFT60-204 & - \\
\hline Cetane index & & 46.136 & 50 & calculated & Min 45.0 \\
\hline $\begin{array}{l}\text { Lower calorific } \\
\text { value }\end{array}$ & $\mathrm{kJ} / \mathrm{kg}$ & 39769.91 & 43.178 & calculated & Min 35000 \\
\hline $\begin{array}{l}\text { Water and volatile } \\
\text { matters content }\end{array}$ & $\%$ & 0.705 & 0.03 & NFT 60-201 & Max 0.05 \\
\hline $\begin{array}{l}\text { Index of } \\
\text { refraction }\end{array}$ & & 1.470 & - & UICPA 2.102 & - \\
\hline Iodine index & $\begin{array}{c}\mathrm{g} \text { of } \\
\text { iodine/100 g }\end{array}$ & 128.185 & - & NF 660 & - \\
\hline Peroxide index & méq of $\mathrm{O}_{2} / \mathrm{kg}$ & 7.375 & - & N E $1-2-50$ & - \\
\hline $\begin{array}{c}\text { Index of } \\
\text { saponification }\end{array}$ & $\mathrm{mg}$ of $\mathrm{KOH} / \mathrm{g}$ & 204.465 & - & NF T 60-220 & - \\
\hline Ester index & $\mathrm{mg}$ of $\mathrm{KOH} / \mathrm{g}$ & 181.44 & - & calculated & - \\
\hline $\begin{array}{c}\text { Content of } \\
\text { insaponifiables }\end{array}$ & $\%$ & 5.57 & - & NF T60-205N & - \\
\hline
\end{tabular}


From the foregoing, it should be noticed that the density, viscosity, and the acidity of the rubber seeds oil are limiting factors for the direct use in a diesel engine. This conclusion is consistent with many authors [2] [4] [15] [33] [38] [46]-[51] when they argue that among the physicochemical characteristics of oils, these parameters cause practical problems. As part of this study, their value far removed from the specifications show that it is not opportune to use such oil in a diesel engine. Therefore, a transformation is needed to be carried out, as it is undertaken using the transesterification method according to Hadamard Matrix.

\subsection{Factor Screening}

The standard deviations of specific gravity and viscosity, estimated by NEMROD-W sofware, were 0.003 and $2.5 \mathrm{cSt}$ respectively. These values validate the chosen experimental field. It therefore appears that specific gravity and viscosity were sensitive to changes in the factors examined. Statistical analysis of the coefficients, illustrated in SM 3, showed that two coefficients had sufficient significance to be taken into account.

These coefficients were $b_{4}$ and $b_{5}$, respectively reflecting the effects of solvent and catalyst. Other factors, such as temperature, stirring speed, and reaction time, were low significance. Calculations using equation (2) indicate that the catalyst and the solvent were responsible for $66.50 \%$ and $32.47 \%$, respectively, of specific gravity variation, for a combined percentage of $98.97 \%$. Similarly, the catalyst and the solvent were responsible for $51.99 \%$ and $35.52 \%$, respectively, of viscosity variation, for a combined percentage of $87.51 \%$.

The coefficient analysis shown in SM 3 demonstrates that use of sulfuric acid, ethanol, a temperature of $80^{\circ} \mathrm{C}$, a stirring speed of $1100 \mathrm{rpm}$, and a reaction time of 145 min leads to a significant decrease in kinematic viscosity and specific gravity and consequently a better transesterification. These results are in agreement with those of several other authors [38] [46]-[51], which suggested that with high-acidity oils (free fatty acid levels $\geq 4 \%$ ), it is preferable to use ethanol and perform acid catalysis transesterification at moderate temperatures and high reaction times.

The results of this screening study indicate that the factors that have the

SM 3. Screening estimated coefficients related to specific gravity.

\begin{tabular}{ccccc}
\hline & \multicolumn{2}{c}{ Specific gravity } & \multicolumn{2}{c}{ Kinematic viscosity } \\
\hline Name & Coefficients & Standard deviation & Coefficients & $\begin{array}{c}\text { Standard } \\
\text { deviation }\end{array}$ \\
\hline b0 & 0.91977 & 0.00126 & b0 & 24.6055 \\
b1 & 0.00048 & 0.00126 & b1 & -0.22976 \\
b2 & -0.00028 & 0.00126 & b2 & -3.32626 \\
b3 & -0.00027 & 0.00126 & b3 & -0.28576 \\
b4 & 0.00348 & 0.00126 & b4 & 5.64499 \\
b5 & $\mathbf{0 . 0 0 4 9 8}$ & 0.00126 & b5 & 6.82924 \\
\hline
\end{tabular}


greatest influence on both the density and the kinematic viscosity of the main product of the transesterification (biodiesel) are type of catalyst and type of alcohol; molar ratios oil/alcohol being fixed to $6: 1$, and the concentrations of the catalysts to $1 \% \mathrm{w} / \mathrm{w}$ and $2.25 \% \mathrm{~mol} / \mathrm{mol}$ respectively for the $\mathrm{KOH}$ and $\mathrm{H}_{2} \mathrm{SO}_{4}$, according to the works of Mohamad et al. (2002) [36]. Both are qualitative factors, so they shall be fixed at the lowest levels $\left(\mathrm{H}_{2} \mathrm{SO}_{4}\right.$ and $\left.\mathrm{EtOH}\right)$ that significantly reduce specific gravity and kinematic viscosity.

\subsection{Quantitative Optimization}

Statistical treatment of the full factorial data revealed that the standard deviations of the responses were 0.0008 and 0.8 cSt respectively for specific gravity and kinematic viscosity. For specific gravity, the correlation coefficient $R^{2}=0.99$ $\geq 0.95$, indicating a good fit for the model illustrated by Equation (4). The evolution of the specific gravity values was consistent with a first-order model. This was not the case with the viscosity, for which the coefficient $R^{2}=0.81 \leq 0.95$. Consequently, a linear model is not sufficient to explain the variation in viscosity, justifying the use of a second-order model.

$$
\begin{aligned}
& Y_{1}\left(X_{1}, X_{2}, X_{3}\right) \cdot 10^{3} \\
& =893.7-4.9 X_{1}-1.4 X_{2}+1.6 X_{3}-2.4 X_{1} X_{2}-0.9 X_{1} X_{3}-0.9 X_{2} X_{3}
\end{aligned}
$$

In the eexperimental field chosen (Table 1), solving this equation leads to the following optimal conditions: $U_{1}=90^{\circ} \mathrm{C}, U_{2}=300 \mathrm{rpm}$, and $U_{3}=125 \mathrm{~min}$, leading to a specific gravity of 0.882 .

These results are consistent with those of Ghanei et al. (2011) [35], who showed that specific gravity follows a linear law during the transesterification reaction.

As Equation (4) indicates, specific gravity variation is strongly influenced by temperature $\left(b_{1}=-0.0049\right)$, which has a positive effect on reduction of the specific gravity of biodiesel. These results are in agreement with those of Betiku et al. (2015) [34]. Indeed, they show that among the independent variables for biodiesel synthesis, temperature had the greatest influence on the reaction yield. As shown in SM 4, specific gravity decreased by $0.0098\left(2^{\star}-0.0049\right)$ when $90^{\circ} \mathrm{C}$ was used instead of $70^{\circ} \mathrm{C}$

The effects of these factors and their interactions on the variation (reduction) in specific gravity of biodiesel during the transesterification reaction have been put into evidence using Equation (2) [28]. The contribution of each factor to the response was calculated using this formula.

The interaction between temperature and stirring speed produced the most important effect, with a coefficient value $b_{12}$ equal to 0.0024 . This interaction can be explained by considering the data shown in SM 5 .

Above the boiling temperature of ethanol $\left(78^{\circ} \mathrm{C}\right)$, strong agitation would be superfluous. On this figure (SM 5), each vertex represents the average value of the responses obtained under the same experimental conditions. When the stirring speed was set at either a high level $(300 \mathrm{rpm})$ or a low level $(100 \mathrm{rpm})$, 
SM 4. Factorial estimated coefficients related to specific gravity.

\begin{tabular}{ccccc}
\hline & \multicolumn{2}{c}{ Specific gravity } & \multicolumn{2}{c}{ Kinematic viscosity } \\
\hline Name & Coefficient & Standard deviation & Coefficient & $\begin{array}{c}\text { Standard } \\
\text { deviation }\end{array}$ \\
\hline b0 & 0.8937 & 0.0002 & 7.082 & 0.006 \\
b1 & -0.0049 & 0.0003 & -0.069 & 0.005 \\
b2 & -0.0014 & 0.0003 & -0.130 & 0.005 \\
b3 & 0.0016 & 0.0003 & 0.071 & 0.005 \\
b12 & -0.0024 & 0.0003 & 0.066 & 0.005 \\
b13 & -0.0009 & 0.0003 & -0.012 & 0.007 \\
b23 & -0.0009 & 0.0003 & 7.082 & 0.006 \\
\hline
\end{tabular}

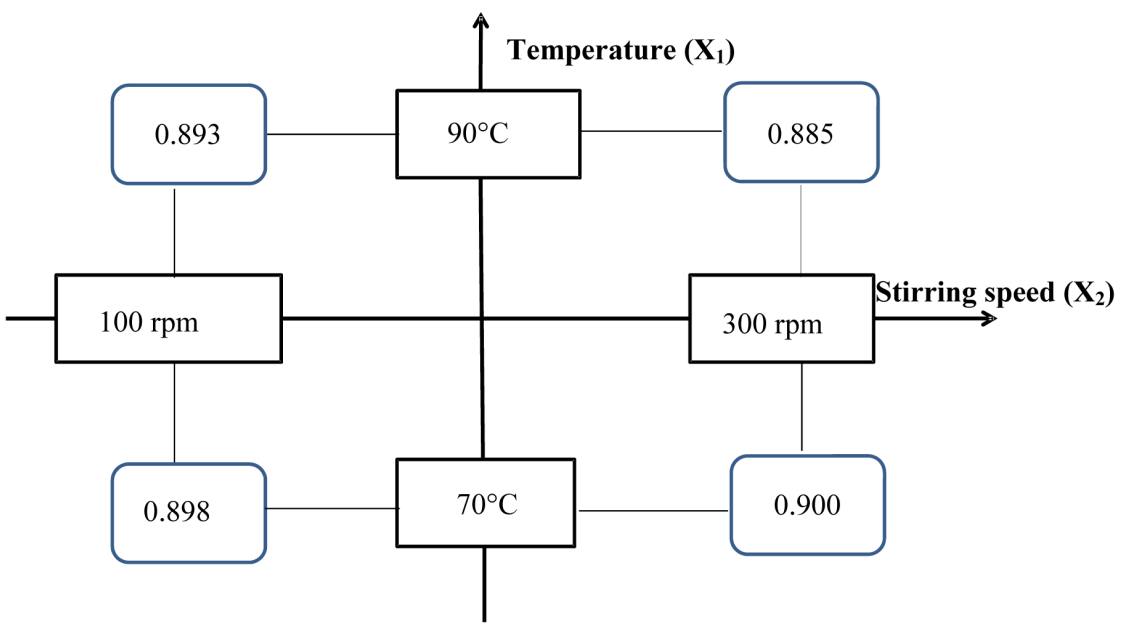

SM 5. Interaction $b_{12}$ between temperature and the stirring speed.

temperature had a significant effect on specific gravity variation. In both cases, specific gravity declined from about 0.90 to about 0.89 , i.e., a reduction of about 0.01 . Consequently, the effect of temperature was dependent on stirring speed. Its negative sign indicates that higher temperatures did not require higher stirring speeds.

\subsection{Viscosity Modeling}

After completion of the experimental tests, the Nemrod-W software was used to analyze the statistical data (shown in SM 5). The experimental response can be described by a nonlinear polynomial model (Equation (5)), as follows:

$$
Y_{2}\left(X_{2}, X_{3}\right) \cdot 10^{3}=7082-69 X_{2}-130 X_{3}+71 X_{2}^{2}+66 X_{3}^{2}
$$

The corresponding correlation coefficient was $R^{2}=0.98 \geq 0.95$, which validates the model, and shows the nonlinearity of the evolution of kinematic viscosity during the transesterification reaction. This model is assumed to be good if the sum of squares due to residuals (i.e., due to fit error) is $\leq 33.33 \%$ of the sum of squares due to the regression [22]. As shown in Table 4, analysis of 
Table 4. ANOVA results for the response surface quadratic model for viscosity variation.

\begin{tabular}{cccccc}
\hline $\begin{array}{c}\text { Source of } \\
\text { variation }\end{array}$ & Sum of squares & $\begin{array}{c}\text { Degrees of } \\
\text { freedom }\end{array}$ & Mean square & Report & Signif. \\
\hline Regression & 0.2327 & 5 & 0.0465 & 273.7684 & $* * *$ \\
Residues & 0.0054 & 7 & 0.0008 & & \\
Validity & 0.0047 & 3 & 0.0016 & 9.2638 & $*$ \\
Error & 0.0007 & 4 & 0.0002 & & \\
Total & 0.2381 & 12 & & \\
\hline
\end{tabular}

variance (ANOVA) indicates that the sum of squares due to error was very low $(0.25 \%)$, confirming that the model was well fitted [52]. The model can be represented by the response surface and contour plot illustrated in Figure 1. In this figure, $X_{1}$ and $X_{2}$ represent the stirring speed and the reaction time, respectively.

Figure 1 shows that kinematic viscosity is lowest in the region where the stirring speed is between $300 \mathrm{rpm}$ and $400 \mathrm{rpm}$ and where the time is between 125 min and $146 \mathrm{~min}$. The best compromise zone leading to minimizing the kinematic viscosity is indicated by the arrow. To determine the extremum (the minimum in the case of this study) of this function, in the chosen experimental domain, the resolution of the system of the relation (6) is necessary.

$$
\left\{\begin{array}{l}
\operatorname{Min} Y_{2}\left(X_{2}, X_{3}\right) \\
-1.414 \leq X_{2} \leq 1.414 \\
-1.414 \leq X_{3} \leq 1.414
\end{array}\right.
$$

On the eexperimental field chosen (Table 1), the optimal conditions obtained by solving this equation (6) are $U_{2}=400 \mathrm{rpm}$ and $U_{3}=145 \mathrm{~min}$, leading to a kinematic viscosity of $6.80 \mathrm{cSt}$.

The difference between the measured responses (Yexp.) and the predicted responses (Ycalc.) from the fitted model did not exceed 5\% [28]. As it can be seen in SM 6, all of the relative deviation values are lower than 5\%. Thus, the secondorder polynomial model described by Equation (5) was satisfactory.

This is consistent with the results of Ghanei et al. (2011) [35], who showed that the viscosity of sunflower oil decreases nonlinearly with an increase of methyl ester wt.\%. Similarly, when the ethyl ester wt.\% in rubber seed oil increases, the kinematic viscosity of the resulting biodiesel decreases nonlinearly.

In short, it should be noted that the specific gravity and the kinematic viscosity of the main product of the transesterification reaction (biodiesel) follow two different models. Thus, a global modeling and optimization process is necessary to find the optimal compromise between these two responses.

\subsection{Global Modeling and Optimization}

Table 3 shows the experimental database, which can be divided into two parts. Runs 1 to 11 represent an extract from the full factorial matrix study, while runs 


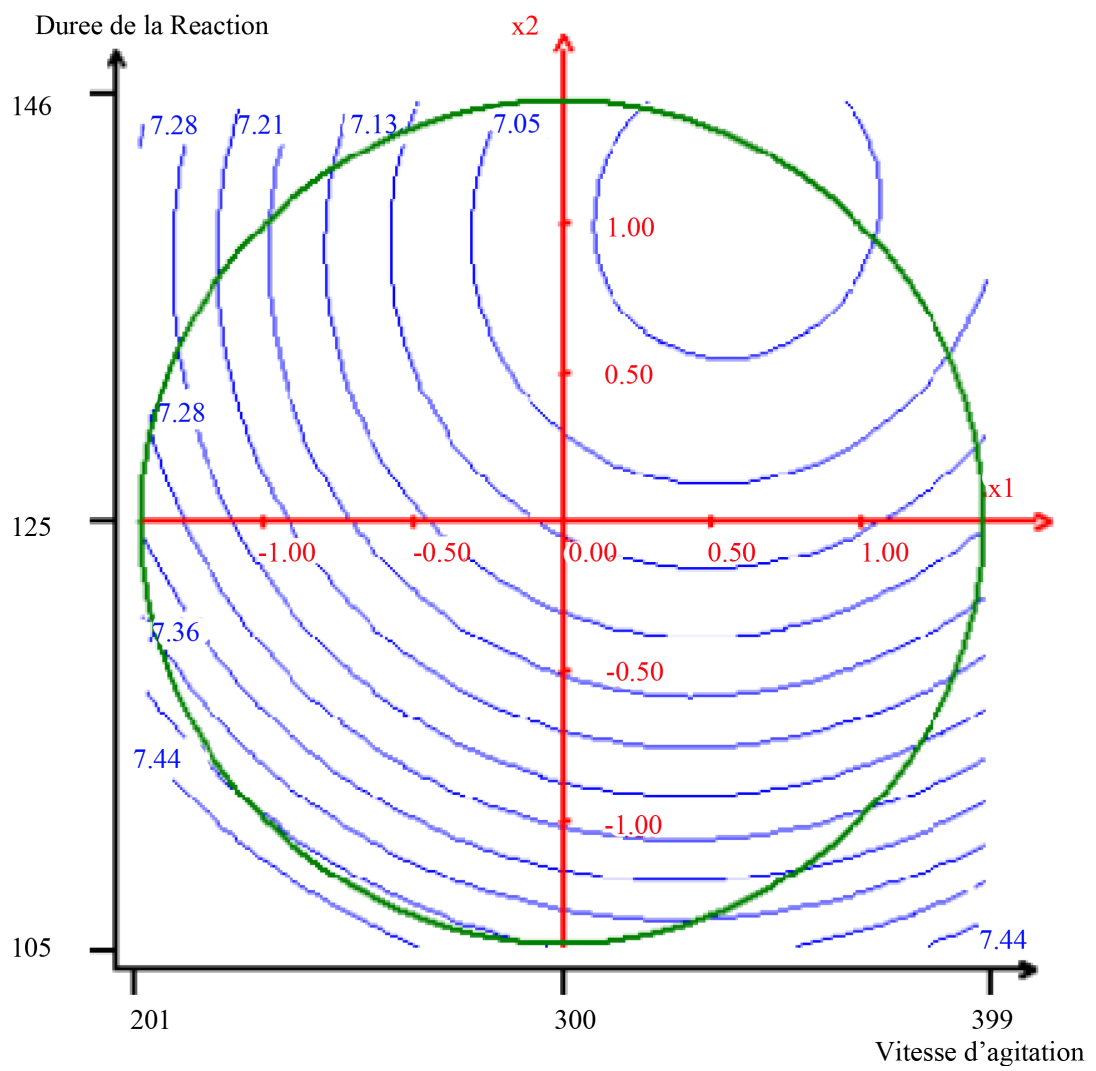

Figure 1. Iso response curve of the viscosity as a function of stirring speed and reaction time.

SM 6. Comparison of measured responses (Yexp.) and predicted responses (Ycalc.).

\begin{tabular}{cccc}
\hline $\mathbf{N}^{\bullet}$ Exp & Yexp. & Ycalc. & Relative deviation \\
\hline 1 & 7.370 & 7.406 & -0.036 \\
2 & 7.260 & 7.293 & -0.033 \\
3 & 7.170 & 7.170 & 0.000 \\
4 & 7.010 & 7.007 & 0.003 \\
5 & 7.340 & 7.321 & 0.019 \\
6 & 7.140 & 7.126 & 0.014 \\
7 & 7.440 & 7.398 & 0.042 \\
8 & 7.020 & 7.029 & -0.009 \\
9 & 7.080 & 7.082 & -0.002 \\
10 & 7.070 & 7.082 & -0.012 \\
11 & 7.070 & 7.082 & -0.012 \\
12 & 7.100 & 7.082 & 0.018 \\
13 & 7.090 & 7.082 & 0.008 \\
\hline & & & \\
\hline
\end{tabular}

12 to 24 are results obtained from a study based on the central composite matrix. Determination of the most powerful architecture, based on mean square error 
(MSE) and correlation coefficient $(R)$, is a key step [40] [41]. Table 5 shows the performance studies for various topologies.

The correlation coefficients $(R)$ varied from 0.9213 to 0.9987 and from 0.9124 to 0.9369 for the training subsets for specific gravity and kinematic viscosity, respectively. For the test subsets, the correlation coefficient varied from 0.8225 to 0.9774 and from -0.2227 to 0.9357 for specific gravity and kinematic viscosity, respectively. When the number of nodes in the hidden layer increased, the correlation coefficients also increased, peaking at the maximum values (0.9987; 0.9369) for the training subset, which is consistent with the results of Assidjo et al. (2008) [41]. For the test subset, the correlation coefficients and the number of neurons in the hidden layer did not evolve in the same direction. The correlation coefficient for specific gravity $\left(Y_{1}\right)$ was higher for an architecture with 8 nodes ( $R=0.9774)$, whereas the correlation coefficient for kinematic viscosity $\left(Y_{2}\right)$ was higher for an architecture with 14 nodes $(R=0.9357)$ in the hidden layer. Thus, it is difficult to find a compromise between the correlation coefficients of the two output variables $\left(Y_{1}, Y_{2}\right)$. Consequently, the MSE values must be considered to find the best network. As it can be seen in Table 5, the lowest MSE value was associated with an architecture with 7 nodes in the hidden layer.

According to Assidjo et al. (2008) [41], the best network is a compromise between the results obtained during training and those with the generalization (test): the network that best characterizes the data of the phenomena is the

Table 5. Performance comparison for one hidden layer ANN structures.

\begin{tabular}{|c|c|c|c|c|c|}
\hline \multirow[b]{3}{*}{ ANN Architecture } & \multirow[b]{3}{*}{ MSE } & \multicolumn{4}{|c|}{ Correlation coefficients (R) } \\
\hline & & \multicolumn{2}{|c|}{ Training set } & \multicolumn{2}{|c|}{ Test set } \\
\hline & & $R_{1}\left(Y_{1}\right)$ & $R_{2}\left(Y_{2}\right)$ & $Y_{1}$ & $R_{3}\left(Y_{2}\right)$ \\
\hline $3-1-2$ & 0.1659259 & 0.92128689 & 0.91239086 & 0.82247118 & 0.72747012 \\
\hline $3-2-2$ & 0.22996692 & 0.99740331 & 0.87870549 & 0.92032353 & 0.67258075 \\
\hline $3-3-2$ & 0.20802504 & 0.99777672 & 0.93682662 & 0.80768482 & 0.58815452 \\
\hline $3-4-2$ & 0.29619335 & 0.9987285 & 0.93693767 & 0.91939178 & 0.83428813 \\
\hline $3-5-2$ & 0.61754245 & 0.99872962 & 0.93693768 & 0.78946941 & 0.79764158 \\
\hline $3-6-2$ & 0.1949534 & 0.99872962 & 0.93693768 & 0.7362596 & 0.79232462 \\
\hline $3-7-2$ & 0.13496578 & 0.99872962 & 0.93693768 & 0.73462176 & 0.90039381 \\
\hline $3-8-2$ & 0.20382485 & 0.99872962 & 0.93693768 & 0.97739648 & 0.70138762 \\
\hline $3-9-2$ & 0.43937642 & 0.99872962 & 0.93693768 & 0.72102712 & -0.30492145 \\
\hline $3-10-2$ & 0.28193651 & 0.99872962 & 0.93693768 & 0.96602334 & 0.90223518 \\
\hline $3-11-2$ & 0.26927229 & 0.99872962 & 0.93693768 & 0.79578759 & -0.39306527 \\
\hline $3-12-2$ & 0.71747384 & 0.99872962 & 0.93693768 & 0.71367914 & -0.22367037 \\
\hline $3-13-2$ & 0.53423457 & 0.99872962 & 0.93693768 & 0.97144311 & 0.64674232 \\
\hline $3-14-2$ & 0.3663114 & 0.99872962 & 0.93693768 & 0.86883668 & 0.9357336 \\
\hline $3-15-2$ & 0.25800042 & 0.99872962 & 0.93693768 & 0.75577645 & 0.87587747 \\
\hline
\end{tabular}


network with the least error. In this study, the best compromise (providing both a low value of MSE and a high value of $R$ for the training and test sets) was obtained with the 3-7-2 structure ANN model depicted in Figure 2.

As Koffi et al. (2006) explained [53], by convention, the relationship is perfect if $R=1$; very strong if $R>0.8$; strong if $R$ is between 0.5 and 0.8 ; medium intensity if $R$ is between 0.2 and 0.5 ; low if $R$ is between 0 and 0.2 ; and zero if $R=0$. In this study, the values of $R$ were 0.94 for specific gravity and 0.91 for viscosity, i.e., very strong in both cases. The comparison between observed and calculated values depicted in Figure 3 also shows the strength of these relationships, confirming that the 3-7-2 ANN architecture best models the relationship between the input variables (temperature, stirring speed, reaction time) and the output variables (specific gravity and kinematic viscosity). However, Ghanei et al. (2011) [35] have shown that these parameters were affected by methyl ester wt.\%. So, there are the relationship between the input variables and the reaction yield.

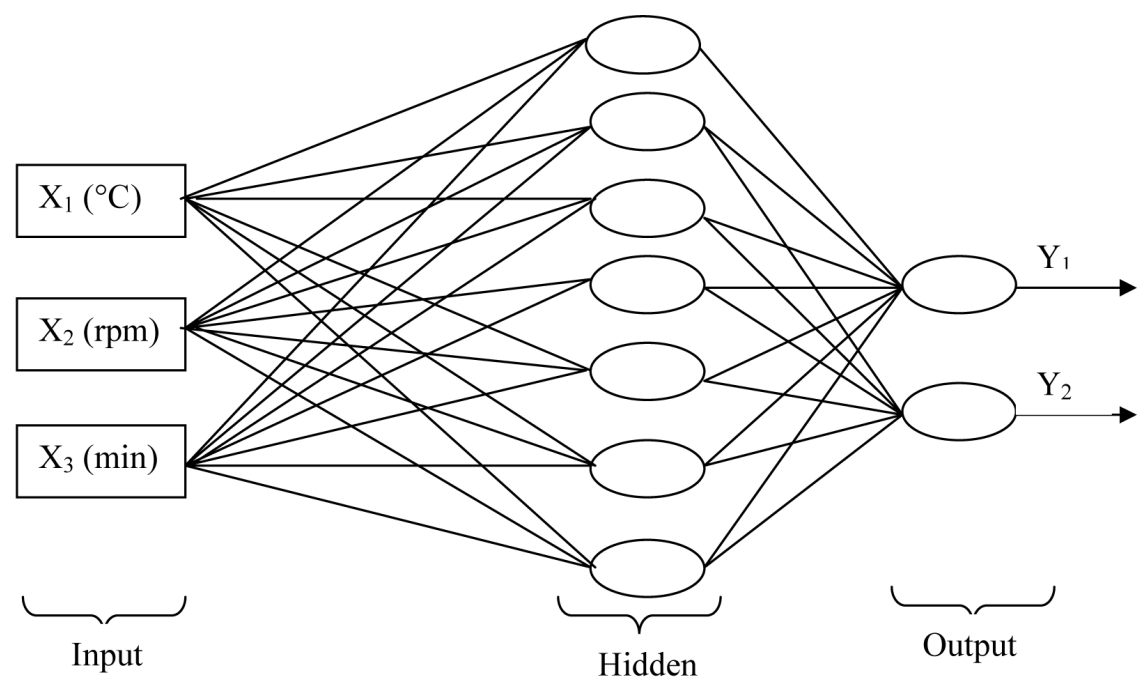

Figure 2. Optimal ANN model.
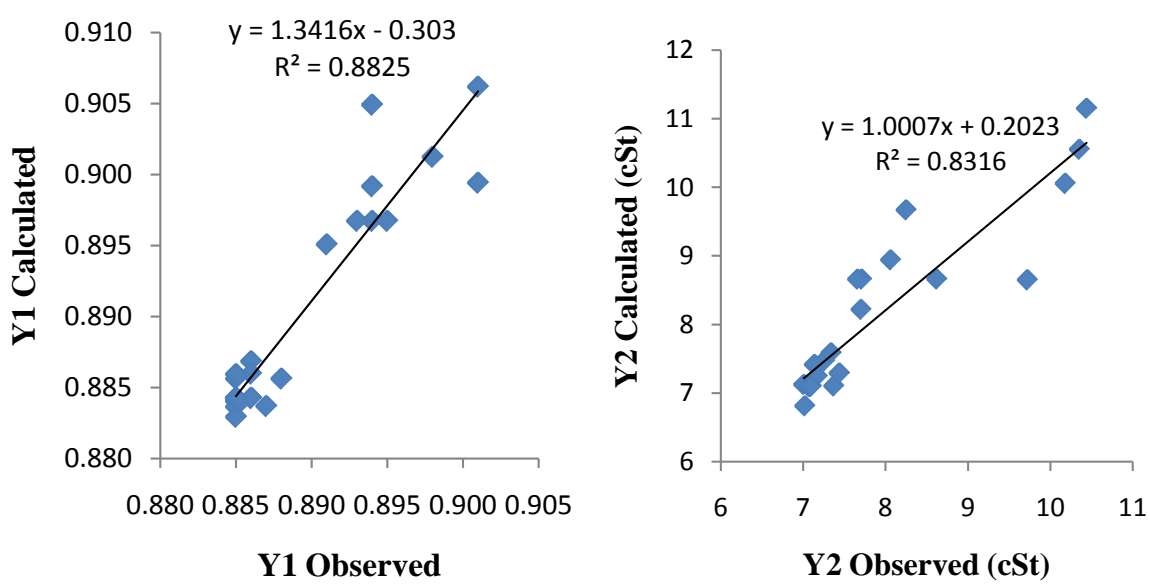

Figure 3. Plots comparing calculated and observed values for the output variables. 
Thus, the 3-7-2 ANN model was found to be highly suitable for modeling the phenomena. Using this model, the multiobjective function described in equation (3) was optimized with the help of a genetic algorithm (GA). The optimal zone, obtained after 1500 iterations, is depicted in Figure 4.

This figure highlights the solution points that minimize both $Y_{1}$ and $Y_{2}$. Note the two parts of the optimal zone represented by curve portions $\mathrm{O}_{1} \mathrm{O}$ and $\mathrm{O}_{2} \mathrm{O}_{3}$. The details of the optimal operating conditions and the corresponding responses are presented in SM 7.

As in Yao et al.'s (2007) study [40], analysis of the effect of each independent variable on the reduction of specific gravity and kinematic viscosity of RSOB shows that the different independent input variables have different effects on the responses of $Y_{1}$ and $Y_{2}$. The results of simultaneous minimization are depicted

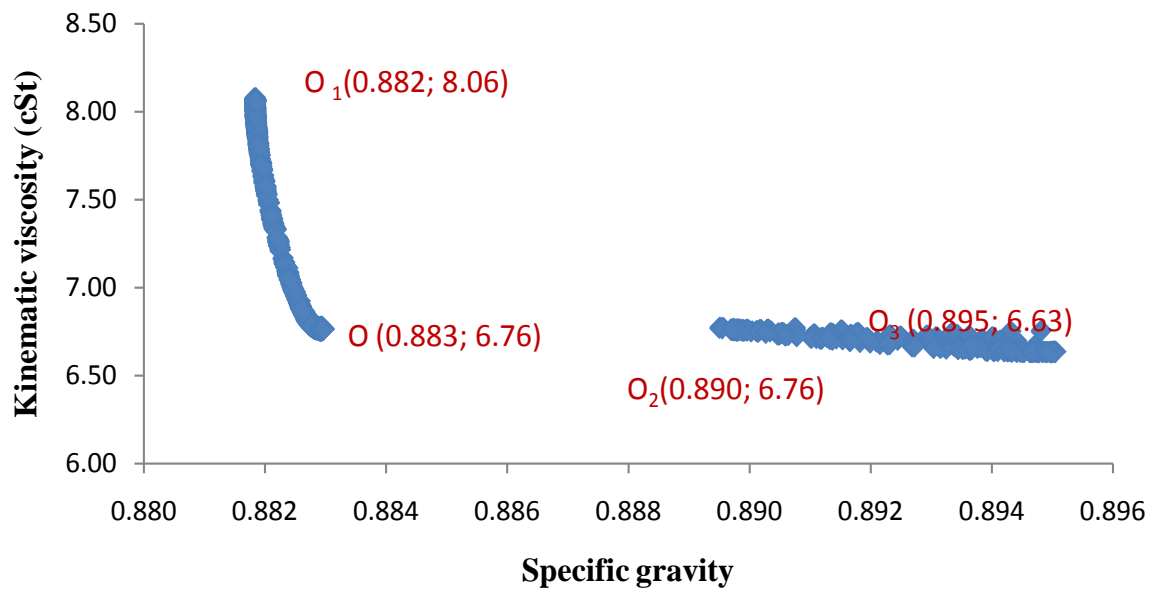

Figure 4. Simultaneous minimization of specific gravity and kinematic viscosity of RSOB.

SM 7. Lower and upper limits obtained after compilation of the GA*.

\begin{tabular}{ccc}
\hline Parameters & Lower limit & Upper limit \\
\hline & \multicolumn{2}{c}{ First zone $\left(\mathrm{O}_{1}-\mathrm{O}\right)$} \\
$X_{1}\left({ }^{\circ} \mathrm{C}\right)$ & 87.14 & 90 \\
$X_{2}(\mathrm{rpm})$ & 305 & 330.21 \\
$X_{3}(\mathrm{~min})$ & 141 & 155 \\
$\mathrm{Y}_{1}$ & 0.882 & 0.883 \\
$Y_{2}(\mathrm{cSt})$ & 6.76 & 8.06 \\
& & Second zone $\left(\mathrm{O}_{2}-\mathrm{O}_{3}\right)$ \\
$X_{1}\left({ }^{\circ} \mathrm{C}\right)$ & 78.96 & 81.3 \\
$X_{2}(\mathrm{rpm})$ & 167.34 & 179 \\
$X_{3}(\mathrm{~min})$ & 105.02 & 105.12 \\
$Y_{1}$ & 0.890 & 0.895 \\
$Y_{2}(\mathrm{cSt})$ & 6.63 & 6.76 \\
\hline
\end{tabular}

${ }^{\star}$ GA. Genetic Algorithm. 
by the pareto front shown in Figure 4 .

The first part of the optimal zone $\left[\mathrm{O}_{1} \mathrm{O}\right]$ is interesting when the goal is to minimize specific gravity, whereas the second part $\left[\mathrm{OO}_{2}\right]$ is interesting when the goal is to minimize kinematic viscosity. To minimize both, a compromise is necessary, and the following recommended operating conditions were proposed: $87.14^{\circ} \mathrm{C} \leq X_{1} \leq 90^{\circ} \mathrm{C} ; 305^{\circ} \mathrm{C} \leq X_{2} \leq 331 \mathrm{rpm} ; 141^{\circ} \mathrm{C} \leq X_{3} \leq 155.89 \mathrm{~min}$.

The optimal point was the couple $\mathrm{O}(0.883 ; 6.76)$, corresponding to a temperature of $90^{\circ} \mathrm{C}$, a stirring speed of $305 \mathrm{rpm}$, and a reaction time of $141 \mathrm{~min}$, as shown by the front of the pareto curve in Figure 4. These results were consistent with those recorded by Betiku et al. (2015) [34].

\subsection{Comparison of Optimization Methods and Experimental Verification of the Model for Biodiesel Production}

Experimental design permitted to make an optimization multiobjective with solver of Excel driving respectively to the minimal values of 0.884 and $6.82 \mathrm{cSt}$ of the specific gravity and the kinematic viscosity in the following conditions: $U_{1}=$ $90^{\circ} \mathrm{C}, U_{2}=400 \mathrm{rpm}$ and $U_{3}=145 \mathrm{~min}$.

As using the ANN coupled to the genetic algoritm, a set of optimal conditions of which most interesting result are the following: $U_{1}=90^{\circ} \mathrm{C}, U_{2}=305 \mathrm{rpm}$, and $U_{3}=141 \mathrm{~min}$. These conditions permitted to have a minimal specific gravity of 0.883 and a kinematic viscosity of $6.76 \mathrm{cSt}$.

Both methods drive to the results of the same order. However, the ANN coupled with the AG permit to have an energizing gain and in time with weaker minimas.

Doing three experiences in the optimal conditions, corresponding to a temperature of $90^{\circ} \mathrm{C}$, a stirring speed of $305 \mathrm{rpm}$, and a duration of $141 \mathrm{~min}$ while using the ethanol as solvent and the sulphuric acid as catalyst, permitted to have the results presented in SM 8.

The averages of the specific gravity and the viscosity kinematics are respectivements $(0.884 \pm 0001)$ and $(6.5 \pm 0.1)$ cSt. While comparing these values to the predicted values, one gets some residues between 0.000 and 0.001 for the density and 0.15 and $0.37 \mathrm{cSt}$ for the viscosity. An agreement almost perfected between the experimental values and the predicted values according to the previous works exists [54] [55] [56]. In our chosen experimental domain, optimization with of the artificial neural networks coupled to the genetic algorithm has been achieved well (the coefficients of variation being lower to 5\%).

SM 8. Experimental verification for the biodiesel production.

\begin{tabular}{cccccccc}
\hline $\mathbf{N}^{\bullet}$ Exp. & $\mathbf{1}$ & $\mathbf{2}$ & $\mathbf{3}$ & Average & $\begin{array}{c}\text { Standard } \\
\text { deviation }\end{array}$ & $\begin{array}{c}\text { Coefficient of } \\
\text { variation }\end{array}$ & $\begin{array}{c}\text { Predicted } \\
\text { value }\end{array}$ \\
\hline $\begin{array}{c}\text { Specifc gravity }\left(Y_{1}\right) \\
\begin{array}{c}\text { Kinematic viscosity } \\
(\mathrm{cSt})\left(Y_{2}\right)\end{array}\end{array}$ & 0.884 & 0.883 & 0.884 & 0.884 & 0.001 & 0.11 & 0.883 \\
\hline
\end{tabular}




\section{Conclusion}

In this paper, a new modeling and optimization approach based on biodiesel quality parameters (kinematic viscosity density) has been realized. It allowed highlighting the relationships between factors that influence the transesterification reaction and biodisel quality parameters. Thus, the present study examined the transformation of rubber seed oil by transesterification, using a Plackett-Burman experimental design, first. Five factors have been examined: temperature, stirring speed, reaction time, type of alcohol, and type of catalyst. Subsequent screening determined that type of catalyst and type of alcohol were the factors that had the most influence on the specific gravity and kinematic viscosity of the main product of the transesterification (biodiesel). High stirring speeds and long reaction time were found to contribute to low kinematic viscosity and low specific gravity. Quantitative optimization showed that changes in the specific gravity of the biodiesel were consistent with a first-order, linear model, while changes in the viscosity followed a second-order model. Global optimization determined that the optimal point for the reaction was a temperature of $90^{\circ} \mathrm{C}$, a stirring speed of $305 \mathrm{rpm}$, and duration of $141 \mathrm{~min}$, leading to a density of 0.883 and a kinematic viscosity of $6.76 \mathrm{cSt}$. Moreover, it is possible to study the effect of these parameters on the cloud point, the calorific value of biodiesel, which are other important fuel parameters.

\section{References}

[1] Hasheminejad, M., Tabatabaei, M., Mansourpanah, Y. and Javani, A. (2011) Upstream and Downstream Strategies to Economize Biodiesel Production. Bioresource Technology, 102, 461-468. https://doi.org/10.1016/j.biortech.2010.09.094

[2] Ayhan, D. (2009) Progress and Recent Trends in Biodiesel Fuels. A Demirbas. Energy Conversion and Management, 50, 14-34. https://doi.org/10.1016/j.enconman.2008.09.001

[3] Srouchi, S. (2006) Master in Information Engineering, Decision and Knowledge. Marseille University Paul Cézanne, Marseille, 22-28.

[4] Gerpen, J.V. and Gerhard, K. (2004) Basic Transesterification of Reaction. 26.

[5] Wafor, O.M.I.N. (2004) Emission Characteristics of Diesel Engine Operating on Rapeseed Methyl Ester. Renewable Energy, 29, 119-129.

https://doi.org/10.1016/S0960-1481(03)00133-2

[6] Felizardo, P., Machado, J. and Vergneiro, D. (2011) Study on the Glycerolysis Reaction of High Free Fatty Acid Oils for Use as Biodiesel Feedstock. Fuel Processing Technology, 92, 1225-1229. https://doi.org/10.1016/j.fuproc.2011.01.020

[7] Balat, M. and Balat, H. (2010) Progress in Biodiesel Processing. Applied Energy, 87, 1815-1835. https://doi.org/10.1016/j.apenergy.2010.01.012

[8] Melero, J.A., Calleja, G., Garcia, A., et al. (2010) Storage Stability and Corrosion Studies of Renewable Raw Materials and Petrol Mixtures: A Key Issue for Their Co-Processing in Refinery Units. Fuel, 89, 554-562.

https://doi.org/10.1016/j.fuel.2009.09.026

[9] Jayed, M.H., Masjuki, H.H., Kalam, M., Mahlia, T.M.I., Husnawan, M. and Liaquat, A.M. (2011) Prospects of Dedicated Biodiesel Engine Vehicles in Malaysia and In- 
donesia. Renewable and Sustainable Energy Reviews, 15, 220-235.

https://doi.org/10.1016/j.rser.2010.09.002

[10] Kumar, A. and Sharma, S. (2011) Potential Non-Edible Oil Resources as Biodiesel Feedstock: An Indian Perspective. Renewable and Sustainable Energy Reviews, 15, 1791-1800. https://doi.org/10.1016/j.rser.2010.11.020

[11] Ashraful, A.M., Masjuki, H.H., Kalam, M.A., Fattah, I.M.R., Imtenan, S., Mobarak, S.A.S. and Mobarak, H.M.S. (2014) Production and Comparison of Fuel Properties, Engine Performance, and Emission Characteristics of Biodiesel from Various Non-Edible Vegetable Oils: A Review. Energy Conversion and Management, 80, 202-228. https://doi.org/10.1016/j.enconman.2014.01.037

[12] Banapurmath, N.R., Tewari, P.G. and Hosmath, R.S. (2008) Performance and Emission Characteristics of a DI Compression Ignition Engine Operated on Honge, Jatropha and Sesame Oil Methyl Esters. Renewable Energy, 33, 1982-1988. https://doi.org/10.1016/j.renene.2007.11.012

[13] Siedouba, Y. and Lebeau, F. (2007) Etude des paramètre opératoires de pressage mécanique des amendes de Vitellaria paradoxa Gaertn C.F. Karité, 11, 1-13.

[14] Vermeersch, G. (1988) Utilisation énergétique des huiles végétales et de leurs produits de la transestérification. Cemagref, BTMEA, No. 30, 10-15.

[15] Abollé, A. (1998) Synthèse de carburants à partir des huiles végétales par craquage catalytique par simulation sur unité pilote. Thèse de Docteur Ingénieur, Université d'Abidjan-Cocody, Abidjan, 133 p.

[16] Likozar, B. and Levec, J. (2014) Transesterification of Canola, Palm, Peanut, Soybean and Sunflower Oil with Methanol, Ethanol, Isopropanol, Butanol and Tert-Butanol to Biodiesel: Modelling of Chemical Equilibrium, Reaction Kinetics and Mass Transfer Based on Fatty Acid Composition. Applied Energy, 123, 108-120. https://doi.org/10.1016/j.apenergy.2014.02.046

[17] Helwani, Z., Othman, M.R., Aziz, N., Fernando, W.J.N. and Kim, J. (2009) Technologies for Production of Biodiesel Focusing on Green Catalytic Techniques: A Review. Fuel Processing Technology, 90, 1502-1514. https://doi.org/10.1016/j.fuproc.2009.07.016

[18] Yusup, S. and Khan, M. (2010) Basic Properties of Crude Rubber Seed Oil and Crude Palm Oil Blend as a Potential Feedstock for Biodiesel Production with Enhanced Cold Flow Characteristics. Biomass \& Bioenergy, 34, 1523-1526. https://doi.org/10.1016/j.biombioe.2010.03.022

[19] Reksowardojo, I.K., Bui, H.N., Sok, R., Kilgour, A.J., Brodjonegoro, T.P., Soerawidjaja, T.H., Pham, M.X., Shudo, T. and Arismunandar, W. (2011) Bandung Institute Teknologi Bandung.

[20] Zhu, Y., Xu, J., Li, Q. and Mortimer, P.E. (2014) Investigation of Rubber Seed Yield in Xishuangbanna and Estimation of Rubber Seed Oil Based Biodiesel Potential in Southeast Asia. Energy, 69, 837-842. https://doi.org/10.1016/j.energy.2014.03.079

[21] Ikwuagwu, O.E., Njoku, I.C.O. and Njoku, O.R.O. (2000) Production of Biodiesel using Rubber [Hevea brasiliensis (Kunth. Muell.)] Seed Oil. Industrial Crops and Products, 12, 57-62. https://doi.org/10.1016/S0926-6690(99)00068-0

[22] Thangaraj, B. and Raj, S.P. (2014) Two-Stage Processes of Homogenous Catalysed Transesterification of High Free Fatty Acid Crude Oil of Rubber Seed. International Journal of Sustainable Energy, 33, 525-535. https://doi.org/10.1080/14786451.2012.761220

[23] Tean, B., Sath, K., Samkol, P. and Ly, J. (2002) Utilization by Pigs of Diets Containing Cambodian Rubber Seed Meal. Livestock Research for Rural Development, 
$14,1-8$.

[24] Herawan, T. (2004) Lipase-Catalyzed of Plant Oils with Transesterification Dialkyl Carbonates. Thesis, Institute BAGKF, Münster, 1-199.

[25] Karmakar, A., Karmakar, S. and Mukherje, S. (2010) Properties of Various Plants and Animals Feedstocks for Biodiesel Production. Bioresource Technology, 101, 7201-7210. https://doi.org/10.1016/j.biortech.2010.04.079

[26] Khan, M.A., Ahmad, M.M. and Yusup, S. (2010) Acid Esterification of High Free Fatty Acid Crude Palm Oil and Crude Rubber Seed Oil Blend: Optimization and Parametric Analysis. Biomass \& Bioenergy, 34, 1751-1756.

https://doi.org/10.1016/j.biombioe.2010.07.006

[27] Goupy, J. (2006) Les plans d'expériences. Revue Modulad, No. 34, 74-116.

[28] Feinberg, M. (1996) The Development of Analytical Methods, a Chemometric Approach to Quality Assurance in the Laboratory. Masson, Paris, 255-271.

[29] Umer, R. and Farooq, A. (2008) Production of Biodiesel through Optimized Alkaline Catalyzed Transesterification of Rapeseed Oil. Fuel, 87, 265-273. https://doi.org/10.1016/j.fuel.2007.05.003

[30] Basak, B.U., Murat, K., Nurgül, Ö., Ays, E.P. and Ersan, P. (2012) Biodiesel Production from Waste Frying Oils: Optimization of Reaction Parameters and Determination of Fuel Properties. Energy, 44, 347-351. https://doi.org/10.1016/j.energy.2012.06.024

[31] Moussavou, M.R.W. (2013) Synthèse enzymatique d'esters éthyliques d'huiles végétales pour la production de biodiesel à l'aide de lipases végétales issues de la biomasse africaine. Thèse de Doctorat, Centre international d'étudessupérieures en sciences agronomiques, Montpellier, $193 \mathrm{p}$.

[32] Nitiema, Y.S.L. (2013) Optimisation de la production du biodiesel éthylique a partir des huiles végétales non conventionnelles. Thèse de Doctorat, de l'Université de Ouagadougou, Burkina Faso, 219 p.

[33] Haïdara, A.O. (1996) Mémoire de Maitrise des Sciences Appliquées. Université de Sherbrooke, Sherbrooke, $137 \mathrm{p}$.

[34] Betiku, E., Okunsolawo, S.S., Ajala, S.O. and Odedele, O.S. (2015) Performance Evaluation of Artificial Neural Network Coupled with Generic Algorithm and Response Surface Methodology in Modeling and Optimization of Biodiesel Production Process Parameters from Shea Tree (Vitellaria paradoxa) Nut Butter. Renewable Energy, 76, 408-417. https://doi.org/10.1016/j.renene.2014.11.049

[35] Ghanei, R., Moradi, G.R., Kalantari, T.R. and Arjmandzadeh, E. (2011) Variation of Physical Properties during Transesterification of Sunflower Oil to Biodiesel as an Approach to Predict Reaction Progress. Fuel Processing Technology, 92, 1593-1598. https://doi.org/10.1016/j.fuproc.2011.04.003

[36] Al-Widyan, M.I. and Al-Shyoukh, A.O. (2002) Experimental Evaluation of the Transesterification of Waste Palm Oil into Biodiesel. Bioresource Technology, 85, 253-256. https://doi.org/10.1016/S0960-8524(02)00135-9

[37] Plackett, R.L. and Burman, J.P. (1946) The Design of Optimum Multifactorial Experiments. Biometrika, 33, 305-325. https://doi.org/10.1093/biomet/33.4.305

[38] Freedman, B., Pryde, E.H. and Mounts, T.L. (1984) Variables Affecting the Yield of Fatty Esters from Transesterified Vegetable Oils. Journal of the American Oil Chemists' Society, 61, 1638-1643. https://doi.org/10.1007/BF02541649

[39] Holland, J.H. (1975) Adaptation in Natural and Artificial Systems. University of Michigan Press, Ann Anbor. 
[40] Yao, K.B., Nogbou, E.A., Ado, G., Azzaro-Pantel, C. and Davin, A. (2007) Modeling and Optimization of M-cresol Isopropylation for Obtaining N-thymol: Combining a Hybrid Artificial Neural Network with a Genetic Algorithm. International Journal of Chemical Reactor Engineering, 5, A87.

[41] Assidjo, E., Yao, B., Kisselmina, K. and Amané, D. (2008) Modeling of an Industrial Drying Process by Artificial Neural Networks. Brazilian Journal of Chemical Engineering, 25, 515-522. https://doi.org/10.1590/S0104-66322008000300009

[42] AFNOR (1999) Fats of Animal and Vegetable Origin. Determination of Acid Value and Acidity: Fats, Oil Seeds, Derivatives: Fats and Derivatives AFNOR, Paris, Volume 1, 313-325.

[43] AFNOR (1988) Fats of Animal and Vegetable Origin. Determination of Unsaponifiable Matter: Fats, Oilseeds, Derivatives: Fats and Derivatives. AFNOR, Paris, Volume 1, 219-223.

[44] Ayuk, P., et al. (1999) Uses, Management and Economic Potential of Irvingia Gabonensis in the Humid Lowlands of Cameroon. Forest Ecology and Management, 113, 1-9. https://doi.org/10.1016/S0378-1127(98)00323-5

[45] Batel, F., et al. (1980) Pflonzenolefur Kraftstoff und die Energieversorgung. Grundlagen der Landtechnik, 40-51.

[46] Zhang, Y., Dube, M.A., McLean, D.D. and Kates, M. (2003) Biodiesel Production from Waste Cooking Oil: 2. Economic Assessment and Sensitivity Analysis. Bioresource Technology, 90, 229-240. https://doi.org/10.1016/S0960-8524(03)00150-0

[47] Canakci, M. and Gerpen, V.J. (1999) Biodiesel Production via Acid Catalysis. Transactions of the ASAE, 42, 1203-1210.

[48] Meneghetti, P.S.M., Meneghetti, M.R., Wolf, C.R., Silva, E.C., Lima, G.H.G., Coimbra, D.A., et al. (2006) Ethanolysis of Castor and Cottonseed Oil: A Systematic Study using Classical Catalysts. Journal of the American Oil Chemists' Society, 83, 819-822. https://doi.org/10.1007/s11746-006-5020-3

[49] Wang, Y., Ou, S., Liu, P., Xue, F. and Tang, S. (2006) Comparison of Two Different Processes to Synthesize Biodiesel by Waste Cooking Oil. Journal of Molecular Catalysis A: Chemical, 252, 107-112. https://doi.org/10.1016/j.molcata.2006.02.047

[50] Widayat, A.D.K. and Wibowo, H. (2013) Study on Process of Producing Biodiesel from Rubber Seed (Hevea brasiliensis) by in Situ (trans)esterification Method with Acid Catalyst. International Conference on Sustainable Energy Engineering and Application, Yogyakarta, 6-8 November 2012.

[51] Widayat, A.D.K., Wibowo, H. and Jos, B. (2012) Study on Production Process of Biodiesel from Rubber Seed (Hevea brasiliensis) by in Situ (Trans)esterification Method. International Review of Mechanical Engineering, 6, 1601-1608.

[52] Zran, E., Yao, B., Trokourey, A., Yobouet, A. and Drogui, P. (2015) An Optimized Pathway for Phosphate Ions Removal from Aqueous Solution Based on Experimental Design Methodology. International Journal of Environmental Science and Technology, 12, 3117-3124. https://doi.org/10.1007/s13762-014-0738-1

[53] Koffi, Y.B., Lasm, T., Ayral, P.A., Anne, J., Kouassi, A.M., Assidjo, E. and Biémi, J. (2006) Optimization of Multi-Layers Perceptrons Models with Algorithms of First and Second Order. Application to the Modelling of Rainfall-Rainoff Relation in Bandama Blanc Catchment (North of Ivory Coast). European Journal of Scientific Research, 17, 313-328.

[54] Koffi, N.E. (2014) Contribution à l'optimisation de l'extraction et à l'étude chimique des polyphénols de deux plantes de Côte d'Ivoire: Tectona grandis Linn (Ver- 
benaceae) et Justicia secunda Vahl (Acanthaceae). Thèse Unique de Doctorat, Université Nangui Abrogoua, Abidjan, 168 p.

[55] Zran, V.E. (2015) Procédés d'élimination des ions phosphates en solution aqueuse par la méthode de la co-précipitation. Thèse Unique de Doctorat, Université Félix Houphouët Boigny Cocody, Abidjan, 152 p.

[56] Fanou, D., Yao, B., Siaka, S. and Ado, G. (2008) Revue Ivoirienne des Sciences et Technologie, 12, 63-76.

\section{Nomenclature}

ANN: Artificial Neural Network

ANOVA: Analysis of Variance

CCD: Central Omposite Design

FFA: Free Fatty Acid

FFD: Full Factorial Design

GA: Genetic Algorithm

MP: Multilayer Perceptron

MSE: Mean Square Error

R: Correlation Coefficient

$\mathrm{R}^{2}$ : Coefficient Of Determination

RSM: Response Surface Methodology

RSO: Rubber Seeds Oil

RSOB: Rubber Seed Oil Biodiesel

SM: Supplementary Material 